Protection against Mosquitos, Flies, and Blight

MR. HAGEN's letter on the destruction of insect-pests (NATURE, vol, xxi. p. 6ri) induces me to make generally known an absolute preventive of the bites of mosquitos, gnats, of green-fly in the vinery, blight in the garden, and a protection to animals from these "insect-pests." A few years ago I had some peach-trees which, being on a wall exposed to draught, were annually blighted. One died, and the new wood of the others was not more than a hand's length. A scientific friend advised me to try a weak solution of quassia to water them with, and the success was complete. Blight was prevented. The first year the trees bore well and the new wood was elbow-length or more. I next tried quassia in the vinery. Instead of lime-washing the walls to get rid of the green-fly, one watering with quassia dismissed them in a day. My head-gardener, who had previously much experience in nursery.grounds, wondered that he had never heard of it before. He now uses it in all cases as a protection from flies and blight. The dilution goes a long way: one pound of chips of quassia-wood boiled and reboiled in other water until he has eight gallons of the extract for his gardenengine. He finds it inadvisable to use it stronger for sorne plants. This boiling makes the quassia adhesive, and being principally applied to the underleaf, because most blight settles there, it is not readily washed off by rain. Quassia is used in medicine as a powerful tonic, and the chips are sold by chemists at from sixpence to a shilling a pound. The tree is indigenous to the West Indies and to South America.

And now as to gnats and mosquitos. A young friend of mine, severely bitten by mosquitos and unwilling to be seen so disfigured, sent for quassia-chips and had boiling water poured upon them. At night, after washing, she dipped her hands into the quassia water and left it to dry on her face. This was a perfect protection, and continued to be so whenever applied. The pastilles sold in Florence and elsewhere, which are vaunted to be safeguards against mosquitos, are, from my own experience, of no use.

At the approach of winter, when flies and grats get into Louses and sometimes bite venomously, a grandchild of mine, eighteen months old, was thus attacked. I gave the nurse some of my weak solution of quassia to be left to dry on his face, and he was not bitten again. It is innocuous to children, and it may be a protection also against bed insects, which I have not had the opportunity of trying. When the solution of quassia is strong it is well known to be an active fly.poison, and is mixed with sugar to attract flies, but this is not strong enough to kill at once. If it be true that mosquitos have been imported into one of the great hotels in the south.west of London, it might be very useful to anoint some of the furniture with it. Then a strong solution with sugar set about the rooms ought to clear them out.

Datlands Park, $;$ Weybridge WM. Chappell

\section{Immersion of Iron and Steel in Acidulated Water}

IN NATURE, vol. xxi. p. 602, I have read an interesting account of Prof. Hughes's experiments on the change produced in iron and steel wire by immersion in acidulated water.

May I ask you to draw the Professor's attention to my experiments on this subject, vide Proceedings of the Literary and Philosophical Society of Manchester, January 7, March 4, December 30, 1873; January 13, March 10 and 24, 1874; and Proceedings of the Royal Society, No. 158, 1875; and a short article in NATURE, I think.

It has long been known to manufacturers of iron wire that iron becomes brittle after immersion in dilute sulphuric or hydrochloric acids. I believe, however, that I was the first to show that this change was due to occluded hydrogen, and by a careful series of experiments to determine approximately the percentage alteration in the breaking strain and elongation at the moment of rupture produced by occluded hydrogen in-

(a) Ordinary or puddled iron wire ;

(b) Iron wire manufactured with charcoal instead of coal ;

(c) Mild or Bessemer steel

(d) Cast steel.

$\mathrm{I}$ also found an increased electrical resistance in wire containing occluded hydrogen, though subsequent experiments have led me to believe that the numbers I first published were too large.

My papers also called attention to the diffusion of hydrogen in iron wire beyond the part immersed in acidulated water; the increase in the length of wire charged with hydrogen and some other phenomena.
The whole subject of the occlusion of hydrogen by metals is one of great interest, and the scientific world will be glad if an accomplished experimenter like Prof. Hughes turns his attention to the subject.

The Ferns, Bowdon, near Manchester, April 26

\section{Stone Arrow Heads}

THE interesting investigations of $\mathrm{Mr}$. Redding on the method of making the above objects, as referred to in NATURE, vol. xxi. p. 6r3, have bcen somewhat anticipated by Mr. Paul Schumacher, "Methods of making stone weapons," Bull. U.S. Geol. and Geog. Survey, vol, iii. p. 547, 1877, which again was a translation from an earlier publication in Archiv fïr Anthropologie, vol. vii. p. 263. Mr. Schumacher's information was derived from the last arrow-maker of a tribe of Klamath Indians, and appears to correspond generally with that obtained by $\mathrm{Mr}$. Redding from the representative of another tribe in the same region. Mr. Schumacher states that obsidian is not the only stone used, but chert, chalcedony, jasper, agate, and similar stones of conchoidal fracture. "The rock is first exposed to fire, and, after a thorough heating, rapidly cooled off, when it flakes readily into sherds of different sizes under well-directed blows at its cleavage." The process is also illustrated in Mr. Schumacher's paper. Superior stone mortars are often found in use amongst these Californian Indians, who deny their capability of making such objects, and account for their possession as "finds" either on the surface or beneath the earth, and describe them as the work of another and previous race.

Derwent Grove, East Dulwich, May I

W. L. Distant

The Mode of Suckling of the Elephant Calf

In some of the accounts recently published of the birth of an elephant in a menagerie in America it is stated that up to this time naturalists had always believed that the elephant calf obtained its mother's milk by means of its trunk, and not directly by the mouth.

Whether this be the case or not, Aristotle was certainly an exception, as the following passage from the twenty-seventh chapter of the sixth book of his "Historia Animalium" (Ed.

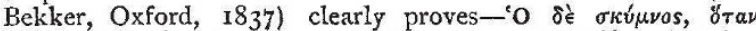

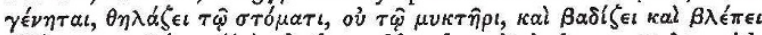
€ìvis $\gamma \in \nu \nu \eta \theta \in i s$. - " And the calf, when it is born, sucks . with its mouth and not with its trunk; and it both walks and sees as soon as it is born." May 3

J. C. G.

\section{The Tay Bridge Inquiry}

IN the Pall Mall of April 21 appeared a report of the evidence of Mr. Henry Law, C.E., in the Tay Bridge inquiry. In this report Mr. Law is made to say: "The heavy girders would fall more rapidly than the carriages; a train moving forward at a great speed would not fall so rapidly as a quiescent structure."

I have been induced to ask your insertion of this note in NATURE in the hope that some of ycur readers who are at home in such matters may confirm or contradict these statements. A person with a mere elementary knowledge of dynamics would disbelieve the latter of them, and would doubt that the former has any practical truth.

Queenwood College, near Stockbridge, Hants

\section{Yeast and Black Beetles}

IN what form should yeast be applied for the destruction of black beetles? If Prof. Lankester will show us how to exterminate them he will earn the gratitude of every

27, Marlborough Hill, N.W., May $\mathbf{I}$

$$
\text { LONDON HOUSEHOLdeR }
$$

Suez Canal Rock Salt.-Dr. Ralton wishes to know where information can be obtained on the subject of the rock salt keds which were cut through in constructing the Suez Canal.

Sodic Chloride CrYstals.-Dr. Ralton asks, what is the action of urea in modifying the crystal form of sodic chloride crystals, referred to by our reviewer of Dr. Ord's book?

[Sotium chloride usually crystallies in cubes; it is stated, however, by Prof. Maskelyne in a lecture before the Royal 